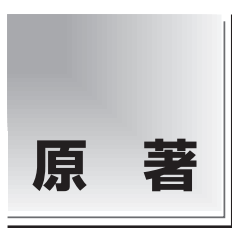

論文受付 2016 年 11 月 29 日

論文受理

2017 年 6 月 6 日

Code No. 251
腎囊胞の CT 画像に生じる pseudoenhancement effect の 抑制に関わる撮影条件の検討：連続 $\mathrm{X}$ 線と仮想単色 $\mathrm{X}$ 線, 画像再構成法，およびビーム幅の違いにおけるファントム検証
杉澤浩一 $^{1,3}$ 市川勝弘 ${ }^{2}$ 南島一也 ${ }^{3}$ 長谷川雅一 $^{3}$ 山田祥岳 $^{4}$ 陣崎雅弘 $^{4}$
緒 言

腎臟腫瘤の computed tomography $(\mathrm{CT})$ を用いた造 影検査を行う際に，不均一な内部構造を呈する腫瘤性
病変に対し，充実性腫瘤か囊胞性腫瘤かを鑑別するこ とは臨床的に非常に重要である。その基準として，造 影画像に打ける腎腫瘤性病変の CT 值が非造影画像と

\title{
Evaluation of the CT Parameters to Suppress Renal Cysts Pseudoenhancement Effect: Influence of the Virtual Monochromatic Spectral Images, the Model-based Iterative Reconstruction Algorithm and the Aperture Size in Phantom Model
}

Koichi Sugisawa, ${ }^{1,2 *}$ Katsuhiro Ichikawa, ${ }^{2}$ Kazuya Minamishima, ${ }^{3}$ Masakazu Hasegawa, ${ }^{3}$ Yoshitake Yamada, ${ }^{4}$ and Masahiro Jinzaki ${ }^{4}$

${ }^{1}$ Graduate School of Medical Science, Kanazawa University

${ }^{2}$ Institute of Medical, Pharmaceutical and Health Sciences, Kanazawa University

${ }^{3}$ Department of Radiological Technology, Keio University Hospital

${ }^{4}$ Department of Diagnostic Radiology, Keio University School of Medicine

Received November 29, 2016; Revision accepted June 6, 2017

Code No. 251

\section{Summary}

Purpose: The purpose of this study was to evaluate the effect of the virtual monochromatic spectral images (VMSI) and the model-based iterative reconstruction (MBIR) images, to evaluate the influence of the aperture size (40- and 20-mm beam) on renal pseudoenhancement (PE) compared with the filtered back projection (FBP) images. Methods: The renal compartment-CT phantom was filled with iodinated contrast material diluted to the attenuation of 180 Hounsfield units (HU) at $120 \mathrm{kV}$. The water-filled spherical structures, which simulate cyst, were inserted into the renal compartment. Those diameters were 7,15 and $25 \mathrm{~mm}$. These were scanned by conventional mode (helical scan, $120 \mathrm{kV}$-FBP) and dual energy mode. $70 \mathrm{keV}$-VMSI were reconstructed from the dual energy mode, and MBIR images were reconstructed from conventional mode at 40- and 20-mm aperture. Additionally, the phantom was scanned using non-helical mode with 20-mm aperture, and FBP images were reconstructed. The CT value of the PE for cyst areas was measured for these images. Results: The CT values of the cysts were 20.0-14.3 $\mathrm{HU}$ on the FBP images, 12.8-12.7 HU on the $70 \mathrm{keV}$-VMSI (PE-inhibition ratio was 36.0-11.2\%) and 16.2-14.0 HU on the MBIR images (19.0-2.1\%), respectively, at 40-mm aperture. The PE-inhibition ratio scanned by $20-\mathrm{mm}$ aperture was improved by $28.0 \%$ with FBP, $32.8 \%$ with $70 \mathrm{keV}$-VMSI and $29.6 \%$ with MBIR compared with 40 $\mathrm{mm}$ aperture. One of the FBP images with non-helical mode was $11.6 \mathrm{HU}$. Conclusions: The best CT technique to minimize PE was the combination of $70 \mathrm{keV}-\mathrm{VMSI}$ and 20 -mm aperture.

Key words: computed tomography (CT), virtual monochromatic spectral image (VMSI), model-based iterative reconstruction (MBIR), aperture size, filtered back projection (FBP), pseudoenhancement effect

*Proceeding author 
比べ, 10 Hounsfield unit (HU) 以上の造影効果をもっ て充実性腫瘤とみなすという報告がなされている ${ }^{1 \sim 5)}$. しかしながら, 従来の造影 $\mathrm{CT}$ 検査では, 腎囊胞の CT 值が造影効果の高い腎実質の影響により高值にシ フトしてしまい，腎腫瘤の鑑別に支障をきたすことが ある。この現象を pseudoenhancement effect $(\mathrm{PE})^{1 \sim 5)}$ と呼び, 考えられる要因として partial volume effect による影響 ${ }^{4 \sim 9)}$ ，および beam-hardening $(\mathrm{BH})$ の影響が

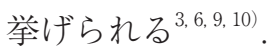

ここで, dual energy 撮影 ${ }^{11)}$ から得られる仮想単色 $\mathrm{X}$ 線 CT 画像 (virtual monochromatic spectral image: VMSI) ${ }^{11 \sim 13)}$, および逐次近似画像再構成法 (model based iterative reconstruction: MBIR)が PE 抑制に有 用と仮定した。この理由として, VMSI は水と造影剂 の 2 種類の物質で $\mathrm{BH}$ を厳密に補正しているこ $と^{12 \sim 17)}$, MBIR は filtered back projection (FBP)に比 ベ画像再構成に統計学的被写体モデルや X 線の発生 に伴う光学的モデルが組み込まれており，原理上，よ り人体に忠実な CT 画像が得られること息 20) が挙げ られる。

腎囊胞の PE に対する基礎研究はいくつか報告され ているが ${ }^{628,10,21)}$, どれも模擬腎囊胞モデルに円柱を用 いており, 臨床上, 囊胞は球体を呈することを考慮す ると，臨床に近似しているとはいいがたい，これらの ことから, 人体に近似したファントムモデルの必要性 を, また検出器の多列化に伴い, 腎囊胞の PE も増大 するという報告 ${ }^{3.7 .10)}$ から，ビーム幅と PE 抑制の関係 を検討する必要性を考えた，PE 抑制でVMSI に着目 した先行研究 ${ }^{21)}$ は存在するものの, VMSI とMBIR お よびビーム幅を同時に評価した基礎研究の報告は存在 しない.

本研究の目的は, 撮影エネルギーの違い (single energy: $120 \mathrm{kV}$ と dual energy: VMSI), 画像再構成法の 違い(FBP と MBIR), およびビーム幅の違い (40 mm と $20 \mathrm{~mm}$ ) に着目し, 球体の模擬腎囊胞を用い, $\mathrm{PE}$ 抑 制に有用な撮影条件を検証することである。

\section{1. 方 法}

\section{1-1 CT 装置}

CT 装置には, 単一 X 線管で $80 \mathrm{kV}$ と $140 \mathrm{kV}$ の二 つの管電圧を高速で切り替える fast $\mathrm{kV}$ switching 方 式で dual energy 撮影を行うことが可能であり，かつ MBIR の画像再構成が可能な Discovery CT750HD (GE Healthcare)を使用した。

\section{1-2 仮想単色 X 線 CT 画像 (VMSI) の原理}

二つの基準物質対を水とヨードとした場合，単一工 ネルギー $E$ の $\mathrm{X}$ 線による投影デー夕 $P$ は, 次式のよ うに求めることができる.

$P=\mu_{w}(E) \cdot d_{w}+\mu_{i}(E) \cdot d_{i}$

ここで, $d_{w}$ は対象物質の水密度, $d_{i}$ は対象物質の ヨード密度, $\mu_{w}$ は水の質量減弱係数, および $\mu_{i}$ はヨー ドの質量減弱係数である。低管電圧 (low) と高管電圧 (high)の 2 種類のエネルギーに扔いて, 投影デー夕 $P_{\text {low }}(i)$ と $P_{\text {high }}(i)$ を取得したとき, 水密度の投影デー夕 $P_{w}(i)$ とヨード密度投影データ $P_{i}(i)$ は (2) と (3) 式の, $P_{\text {low }}(i)$ と $P_{h i g h}(i)$ を含む多項式として表される.

$$
\begin{aligned}
P_{w}(i)= & \alpha_{1}(i) P_{\text {low }}(i)+\beta_{1}(i) P_{\text {high }}(i)+\chi_{1}(i) P_{\text {low }}^{2}(i) \\
& +\delta_{1}(i) P_{\text {high }}^{2}(i)+\varepsilon_{1}(i) P_{\text {low }}(i) P_{\text {high }}(i) \cdots
\end{aligned}
$$

$$
\begin{aligned}
P_{i}(i)= & \alpha_{2}(i) P_{\text {low }}(i)+\beta_{2}(i) P_{\text {high }}(i)+\chi_{2}(i) P_{\text {low }}^{2}(i) \\
& +\delta_{2}(i) P_{\text {high }}^{2}(i)+\varepsilon_{2}(i) P_{\text {low }}(i) P_{\text {high }}(i) \cdots
\end{aligned}
$$

これらの多項式の係数を, 最小 2 乗法を用いて導き

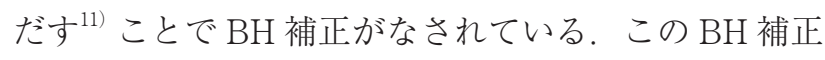
がなされた $P_{w}(i)$ と $P_{i}(i)$ を用いて，(1)式より，物質 の質量減弱係数は既知であることから，それぞれの密 度 $d_{w}$ と $d_{i}$ が得られ, 最終的に, 各 photon energy に おける投影值 $P$ を計算することでVMSI が取得でき

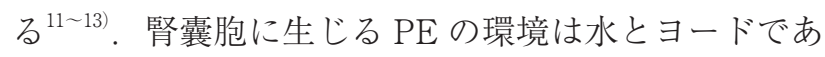
ることを考慮すると, 二つの基準物質対 (水とヨード) に対し，厳密にBH 補正がなされているVMSI は理論 上, $\mathrm{PE}$ の抑制効果が期待できる。

\section{1-3 逐次近似画像再構成法 (MBIR) の概要}

画像再構成に必要な個々の view angle は, まず対象 物のイメージを影絵のように投影することによって求 める. これはX X 線の光子が対象物を透過し, 各検出 器で収集されるが，実際には，この view に沿ったX 線の減衰があるため, 本来のプロジェクションデー夕 と仮想プロジェクションデータで大きな違いが生じ る。更に，これはX線焦点サイズを現実的な大きさ (点ではない)として捉え, X 線管モデルを通して考え る. 同様に, 検出器のサイズや形は, 検出器レスポン ス関数のモデルを通して計算される，焦点一検出器間 を通る光子束の通過ポイントを点ではなく, ボクセル の大きさとして考える. その大きさや形は, X線相互 作用の影響により異なった方向と位置でボクセルに入 


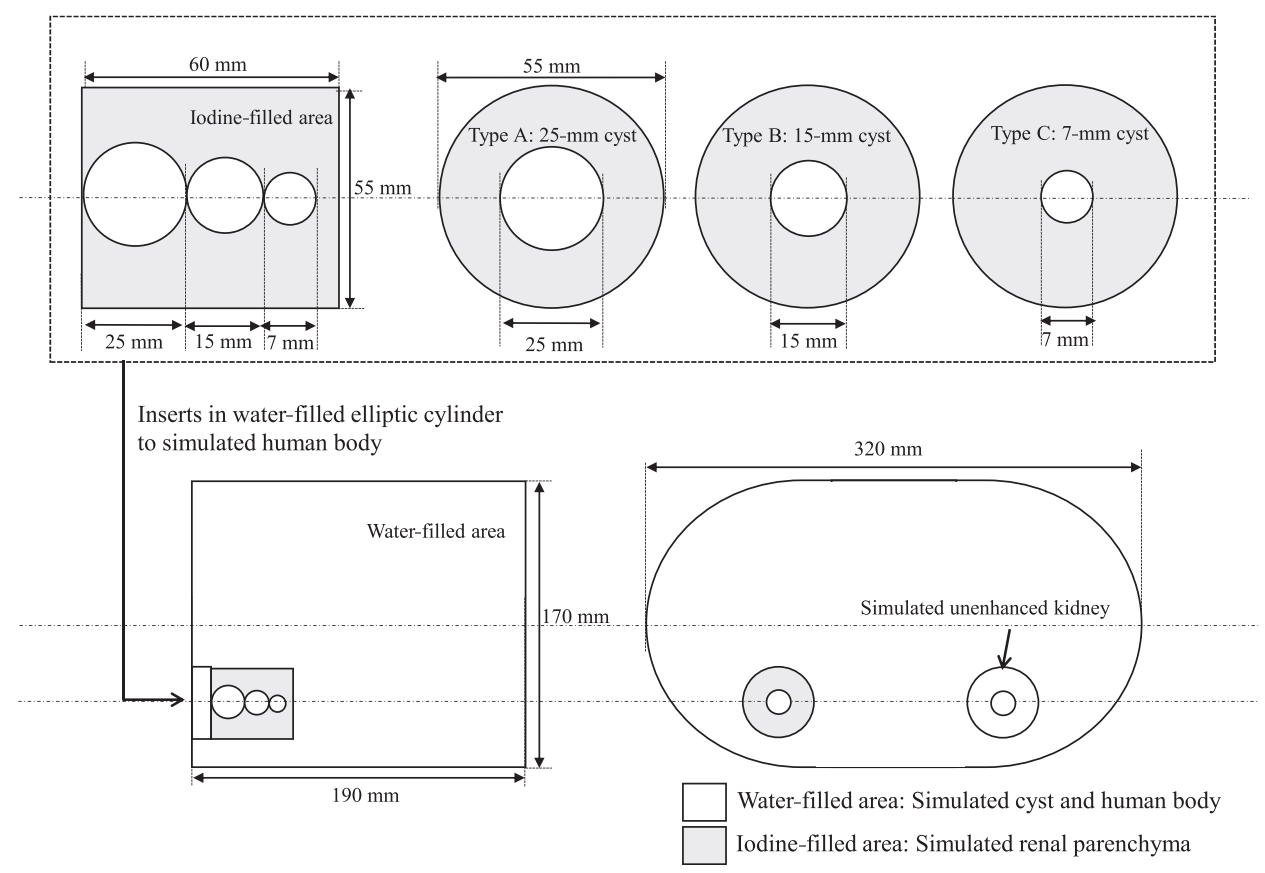

Fig. 1 Schema of the renal parenchyma-phase cyst compartment phantom simulating human body. White part is cyst area, which is filled with water. Grey part is parenchyma area, which has attenuation of $180 \mathrm{HU}$ decided enhanced renal parenchyma on clinical setting.

るX 線光子のために, 通過経路の長さが異なるモデ ルとして考えられる.

MBIRでは, 光学モデルを計算システムに取り入 れ，実際に得られた生デー夕と画像から投影された仮 想生データの間でどのくらい誤差があるのか計測し, 画像再構成時に，この違いを最小にしていく，結果と して密度分解能や空間分解能の向上を図り, データ矛 盾から生じるアーチファクトが抑制される ${ }^{18,19)}$ 。腎囊 胞に生じる PE をデータ矛盾から生じたアーチファク 卜と捉えた場合, MBIR は理論上, PE 抑制効果が期待 できる。

\section{1-4＼cjkstart模擬腎囊胞ファントムの構成}

腎臓を模擬した径 $55 \mathrm{~mm}$ の円柱(材質はポリエチ レン製)内に，径 $7 \mathrm{~mm} ， 15 \mathrm{~mm}$ ，および $25 \mathrm{~mm}$ の腎 囊胞領域を模擬7,10) するため, 水 (CT 值：0 HU) を充 填させた球体 (材質はポリプロピレン製の中空構造)を 中心に挿入した，腎臓を模擬した円柱の径は，臨床例 (30 例)における腎臓の平均径である。また, 模擬囊胞 を模擬腎内中心に配置したのは，PEの影響を受けや すい状況を作り出し, かつ, 実臨床に近似した CT 值 を確保するためである。次に造影された腎実質領域を 模擬するため, $120 \mathrm{kV}$ 撮影において CT 值 $180 \mathrm{HU}$ 付 近 ${ }^{22)} に$ 希勫した造影剂を，腎囊胞を模擬した球体の周 囲に充填し，実質相における腎囊胞を模擬した。この 腎実質相の CT 值は, 撮像タイミング：造影剂注入後
70 秒，造影剤注入量：600 mgI/ $\mathrm{kg}$ ，および注入時間： 30 秒で得られた 31 症例の平均值である ${ }^{22)}$ 。この腎囊 胞ファントムを, 人体を考慮した長径 $320 \mathrm{~mm}$, 短径 $170 \mathrm{~mm}$ の楕円柱水ファントム (材質はアクリル製)内 に挿入し被写体厚を模擬した(Fig. 1).

\section{1-5 撮影条件および画像再構成条件}

スキャンタイプ: helical (pitch factor: 1.375), 管電 圧： $120 \mathrm{kV}$, 画像再構成法: FBP, およびビーム幅： $40 \mathrm{~mm}(64 \times 0.625 \mathrm{~mm}$ のディテクタ構成)の撮影を従 来法とした。撮影線量は, 実臨床と同等にするため volume CT dose index $\left(\mathrm{CTDI}_{\mathrm{vol}}\right): 12 \mathrm{mGy}$ とした。 Scan field of view (SFOV)および display field of view (DFOV) はそれぞれ large body (有効視野：500 mm), $350 \mathrm{~mm}$ を使用した。画像再構成スライス厚は partial volume effectによる影響を最小限にするべく $\mathrm{mm}$ を用いた，画像再構成フィルタは standard(腹部 標準関数)を用いた。 Dual energy の撮影では, 従来法 と同等の $\mathrm{CTDI}_{\mathrm{vol}}: 12 \mathrm{mGy}$ となるよう管電流 : 600 $\mathrm{mA}$ とし, $120 \mathrm{kV}$ の画像と同等である $70 \mathrm{keV}^{14,15,22)}$ のVMSI を取得した。MBIR 画像は, 従来法から画像 再構成し取得した。 またスキャン回数は 10 回とした.

\section{1-6CT值による比較}

10 回スキャンにおける 3 種類の模擬腎囊胞サイズ (7 mm, $15 \mathrm{~mm}$ ，および $25 \mathrm{~mm}$ )に対し, ベース(非造 


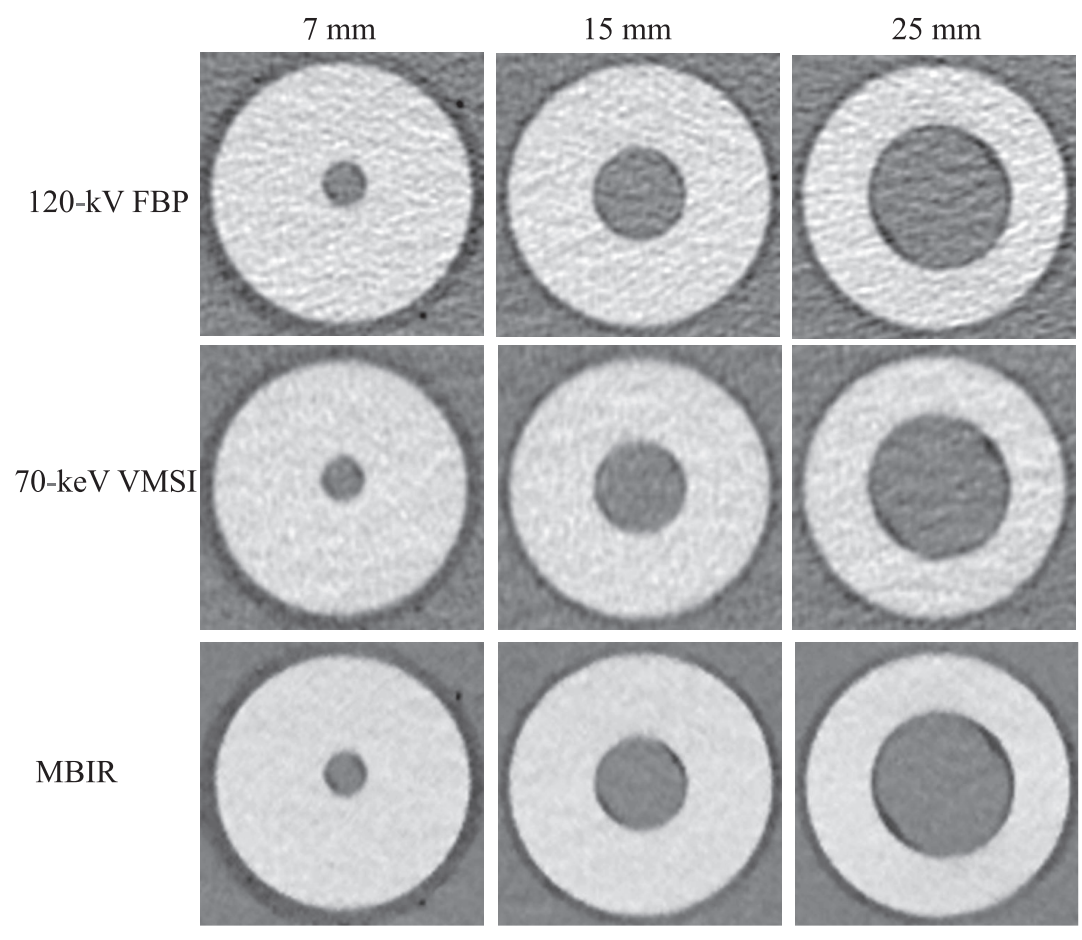

\begin{tabular}{l|l|l}
$a$ & $b$ & $c$ \\
\hline$d$ & $e$ & $f$ \\
\hline$g$ & $h$ & $i$
\end{tabular}

Fig. 2 CT images of the cyst with the simulated renal parenchyma-phase at the phantom.

(a) 7-mm cyst with $120-\mathrm{kV}$ FBP, (b) $15-\mathrm{mm}$ cyst with $120-\mathrm{kV}$ FBP, (c) $25-\mathrm{mm}$ cyst with $120-\mathrm{kV}$ FBP, (d) 7-mm cyst with 70-keV VMSI, (e) 15-mm cyst with 70-keV VMSI, (f) 25-mm cyst with 70-keV VMSI, (g) 7-mm cyst with MBIR, (h) 15-mm cyst with MBIR, (i)25-mm cyst with MBIR

影時の模擬腎囊胞)，模擬腎実質，および実質相(造影 時)における模擬腎囊胞内の CT 值を計測, その平均 值を算出した．計測には模擬腎囊胞の対象径の 2 分の 1 の径を有する region of interest(ROI)を用いた

得られたデータの統計解析には 3 群に対する Bonferroni 補正を行った $\mathrm{t}$ 検定 (significance level : 5\%)による多重比較を用いた.

また，従来法における模擬腎囊胞領域の CT 值 $\left(R O I_{\text {conventional }}\right)$ ，それぞれの撮影手技で取得した画像に おける模擬腎囊胞領域の $\mathrm{C} T$ 值 $\left(R O I_{\text {target method }}\right)$ から次 式により PE 抑制率 (inhibition ratio)を算出した。

Inhibition ratio(\%) $=$

$$
\left(\frac{R O I_{\text {conventional }}-R O I_{\text {tagetmethod }}}{R O I_{\text {conventional }}}\right) \times 100
$$

1-6-1 撮影エネルギー (single-vs. dual-energy)の違 いによる PE 抑制効果

従来法である single energy 撮影 $(120 \mathrm{kV}-\mathrm{FBP})$ と

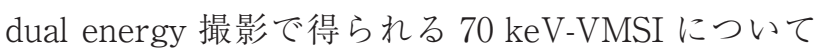
ベース, 模擬腎実質, および実質相模擬腎囊胞の CT 值の比較を行った。

\section{1-6-2 画像再構成法 (FBP vs. MBIR)の違いによる}

\section{PE 抑制効果}

従来法で用いた画像再構成法である FBP と MBIR
についてベース, 模擬腎実質, および実質相模擬腎囊胞 領域の CT 值の比較を行った。また, 1-6-1 で得られた 70 keV-VMSI と MBIR 群間の CT 值の比較も行った。

1-6-3 ビーム幅 (40-vs. 20-mm)の違いによる PE 抑 制効果

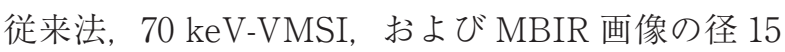
$\mathrm{mm}$ の模擬腎囊胞サイズについて, ビーム幅 $40 \mathrm{~mm}$ と $20 \mathrm{~mm}$ の違いに扔けるべース, 模擬腎実質, およ び実質相模擬腎囊胞領域の CT 值の比較を行った。ま た，FBPに関しては non-helical scan, ビーム幅 20 $\mathrm{mm}$ を追加した。撮影条件は 1-5 に準じた。

\section{2. 結 果}

2-1 撮影エネルギー( single-vs. dual-energy)の違い による PE 抑制効果

従来法 $(120 \mathrm{kV}-\mathrm{FBP})$ と $70 \mathrm{keV}-\mathrm{VMSI}$ の比較であ る. CT 画像を Fig. 2a〜fに示す. 120 kV-FBP， およ び $70 \mathrm{keV-VMSI} に$ におるべースの平均 CT 值は, 径 7

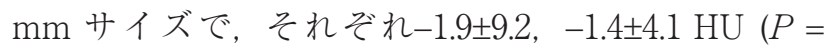
1.0)，径 $15 \mathrm{~mm}$ サイズで，それぞれ $0.2 \pm 4.2,-1.1 \pm 2.1$ $\mathrm{HU}(P=1.0)$, および径 $25 \mathrm{~mm}$ サイズで, それぞれ $1.6 \pm$ 1.3, $1.7 \pm 0.9 \mathrm{HU}(P=1.0)$ であった(Table 1).

模擬腎実質の平均 $\mathrm{CT}$ 值は, 径 $7 \mathrm{~mm}$ サイズで, そ れぞれ $173.7 \pm 1.5,174.3 \pm 1.5 \mathrm{HU}(P=1.0)$, 径 $15 \mathrm{~mm}$ サ 
Table 1 Averaged CT attenuation values of the 7-, 15-, and 25-mm cyst in simulated unenhanced kidney (base); of the simulated renal parenchyma; of those cysts in the simulated renal parenchyma phase with $40-\mathrm{mm}$ aperture. The inhibition ratio of pseudoenhancement effect for $70 \mathrm{keV}$-VMSI, and MBIR compared with $120 \mathrm{kV}-\mathrm{FBP}$.

\begin{tabular}{lcccc}
\hline \hline Protocol & $\begin{array}{c}\text { Cyst diameter } \\
{[\mathrm{mm}]}\end{array}$ & $\begin{array}{c}\text { Cyst areas in the } \\
\text { non-contrast images }\end{array}$ & $\begin{array}{c}\text { CT attenuation value }[\mathrm{HU}] \\
\text { Parenchymal areas } \\
\text { around the cyst }\end{array}$ & $\begin{array}{c}\text { Cyst areas in the } \\
\text { contrast images }\end{array}$ \\
\hline $120 \mathrm{kV}$-FBP & 7 & $-1.9 \pm 9.2$ & $173.7 \pm 1.5$ & $20.0 \pm 4.5$ \\
& 15 & $0.2 \pm 4.2$ & $179.0 \pm 2.4$ & $16.1 \pm 3.5$ \\
& 25 & $1.6 \pm 1.3$ & $177.4 \pm 2.9$ & $14.3 \pm 2.1$ \\
\hline $70 \mathrm{keV}-$ VMSI & 7 & $-1.4 \pm 4.1$ & $174.3 \pm 1.5$ & $12.8 \pm 7.3(36.0 \%)$ \\
& 15 & $-1.1 \pm 2.1$ & $177.9 \pm 1.5$ & $12.6 \pm 1.8(21.8 \%)$ \\
& 25 & $1.7 \pm 0.9$ & $176.5 \pm 3.2$ & $12.7 \pm 1.5(11.2 \%)$ \\
\hline MBIR & 7 & $0.3 \pm 3.4$ & $173.2 \pm 1.2$ & $16.2 \pm 3.4(19.0 \%)$ \\
& 15 & $0.5 \pm 1.9$ & $178.8 \pm 1.5$ & $15.8 \pm 2.3(1.9 \%)$ \\
& 25 & $1.0 \pm 1.2$ & $176.9 \pm 2.2$ & $14.0 \pm 1.1(2.1 \%)$ \\
\hline
\end{tabular}

Values in bracket: inhibition ratio
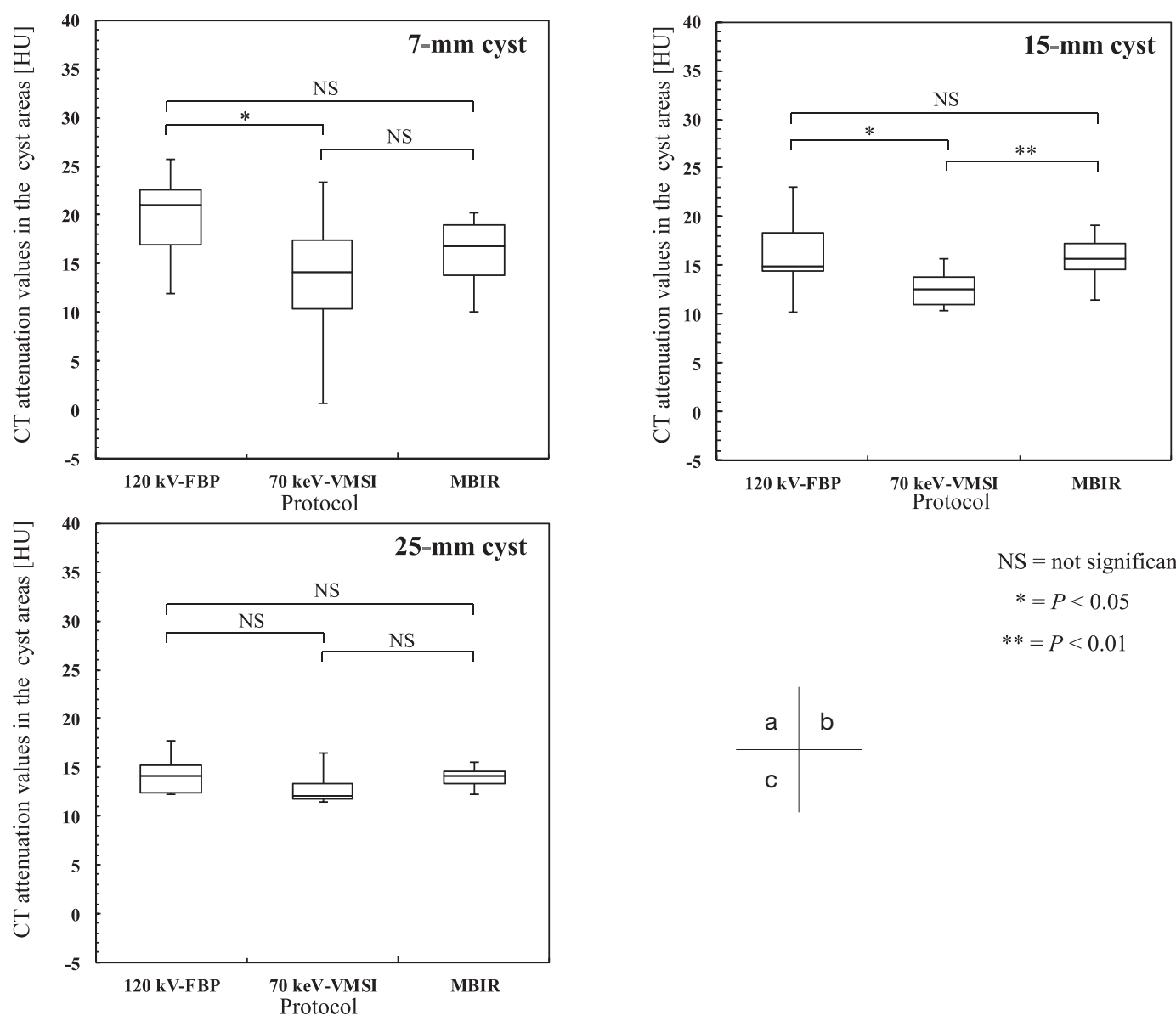

NS $=$ not significant

$*=P<0.05$

$* *=P<0.01$

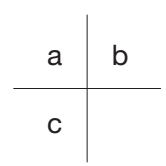

Fig. 3 Comparison of the cyst-CT attenuation values in the simulated renal parenchyma-phase with $120 \mathrm{kV}$ FBP, $70 \mathrm{keV}-\mathrm{VMSI}$ and MBIR.

(a) 7-mm cyst, (b) 15-mm cyst, (c) 25-mm cyst NS=not significant, $*=P<0.05, * *=P<0.01$

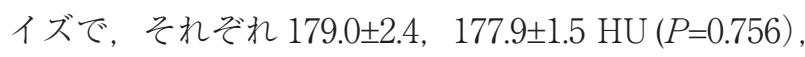
および径 $25 \mathrm{~mm}$ サイズで，それぞれ 177.4 $3.2 \mathrm{HU}(P=1.0)$ であった (Table 1).

実質相模擬㹂囊胞領域の平均 CT 值は, 径 $7 \mathrm{~mm}$ サ

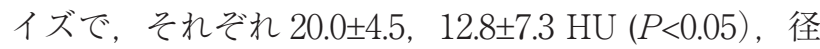

$15 \mathrm{~mm}$ サイズで，それぞれ $16.1 \pm 3.5 ， 12.6 \pm 1.8 \mathrm{HU}(P<$ 0.05)，および径 $25 \mathrm{~mm}$ サイズで，それぞれ $14.3 \pm 2.1$,

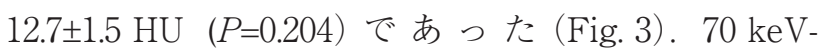
VMSI の PE 抑制率を Table 1 に示す. 


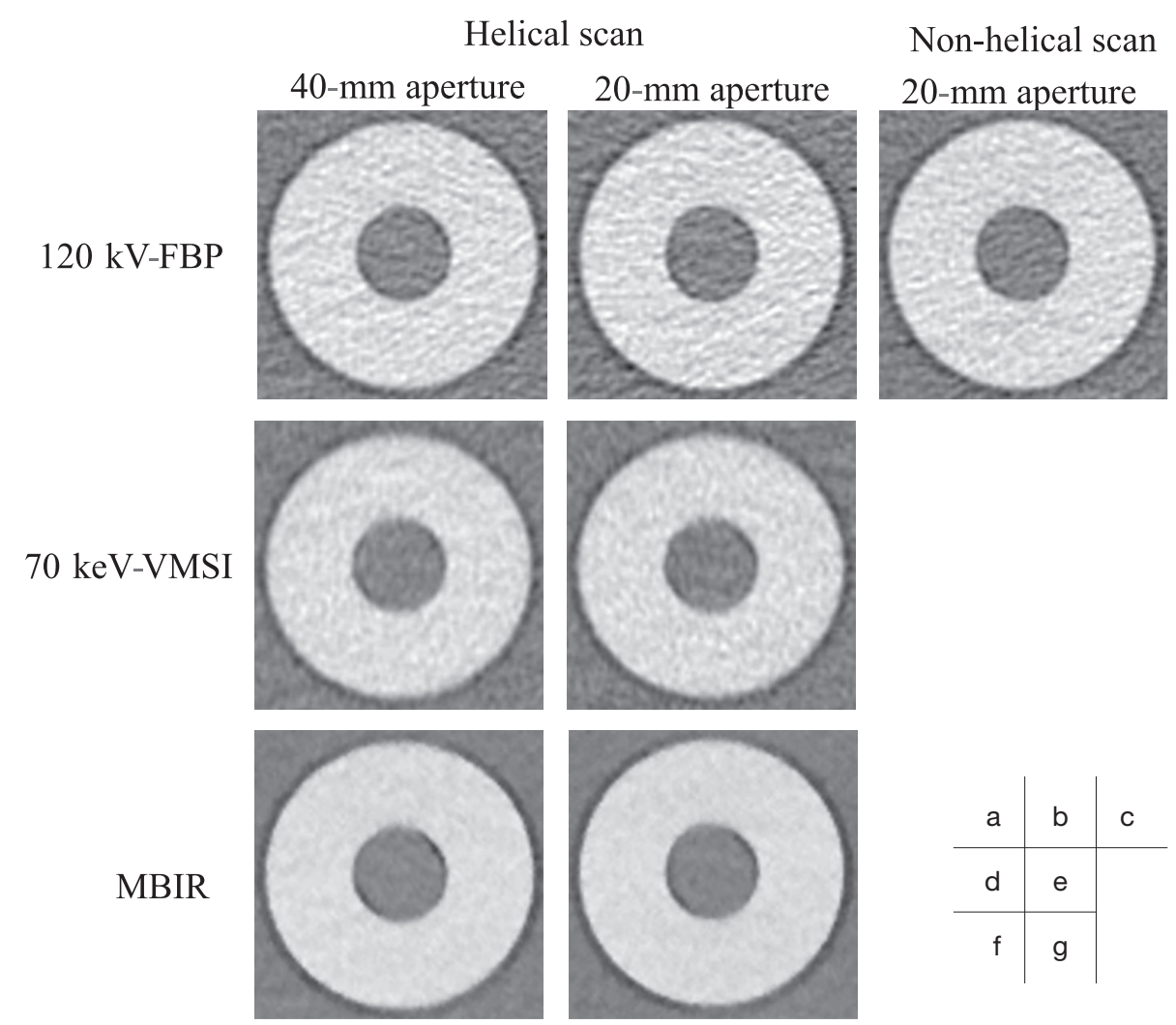

Fig. 4 CT images of the 15-mm cyst with the simulated renal parenchyma-phase at the phantom. (a) $120 \mathrm{kV}$-FBP helical 40-mm aperture, (b) $120 \mathrm{kV}$-FBP helical $20-\mathrm{mm}$ aperture, (c) $120 \mathrm{kV}$ FBP non-helical 20-mm aperture, (d) $70 \mathrm{keV}$-VMSI helical 40-mm aperture, (e) $70 \mathrm{keV}$-VMSI helical 20-mm aperture, (f) MBIR helical 40-mm aperture, (g) MBIR helical 20-mm aperture

\section{2-2＼cjkstart画像再構成法 (FBP vs. MBIR)の違いによる PE 抑制効果}

従来法(FBP) と MBIR の比較である. MBIR の CT 画像を Fig. $2 \mathrm{~g} \sim \mathrm{i}$ に示す. MBIR に扔けるべースの平 均 CT 值は, 径 $7 \mathrm{~mm}$ サイズ, 径 $15 \mathrm{~mm}$ サイズ，およ び径 $25 \mathrm{~mm}$ サイズで，それぞれ $0.3 \pm 3.4(P=1.0), 0.5 \pm$ $1.9(P=1.0)$, および $1.0 \pm 1.2 \mathrm{HU}(P=0.872)$ であった

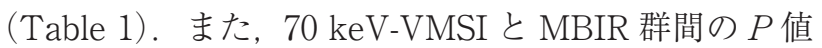
は，それぞれ $1.0 ， 0.273$ ，および 0.507 であった。

模擬腎実質の平均 CT 值は, 径 $7 \mathrm{~mm}, 15 \mathrm{~mm}$, およ び $25 \mathrm{~mm}$ サイズで，それぞれ $173.2 \pm 1.2 \mathrm{HU}(P=1.0)$, $178.8 \pm 1.5 \mathrm{HU}(P=1.0)$, および $176.9 \pm 2.2 \mathrm{HU}(P=1.0)$ で

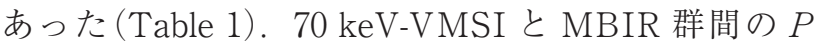

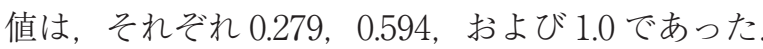

実質相模擬腎囊胞領域の平均 CT 值は, 径 $7 \mathrm{~mm}$ サ イズ，径 $15 \mathrm{~mm}$ サイズ，および径 $25 \mathrm{~mm}$ サイズで,

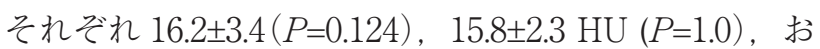
よび $14.0 \pm 1.1 \mathrm{HU}(P=1.0)$ であった (Fig. 3). $70 \mathrm{keV}$ VMSI と MBIR 群間の $P$ 值は，それぞれ $0.663,<0.01$, および 1.0 であった. MBIR の PE 抑制率を Table 1 に示す.
2-3 ビーム幅 (40-vs. 20-mm)の違いによる PE 抑制 効果

ビーム幅 $40 \mathrm{~mm}$ と $20 \mathrm{~mm}$ の比較を, プロトコル (FBP, 70 keV-VMSI および MBIR)ごとに行った. CT 画像を Fig. 4 に示す。ビーム幅 $20 \mathrm{~mm}$ における ベースの平均 CT 值は helical-FBP, non-helical-FBP, $70 \mathrm{keV}-\mathrm{VMSI}$ ，およびMBIR で，それぞれ $0.7 \pm 3.0(P=$ 1.0), $0.2 \pm 1.5(P=1.0), 0.1 \pm 1.4(P=0.147)$ ，および $0.7 \pm 1.5$ HU $(P=0.84)$ であった (Table 2).

模擬腎実質の平均 CT 值は helical-FBP, non-helicalFBP, 70 keV-VMSI，およびMBIRで，それぞれ 179.8 $\pm 1.7 \mathrm{HU}(P=1.0), 179.3 \pm 1.7 \mathrm{HU}(P=1.0), 178.2 \pm 1.6 \mathrm{HU}$ $(P=0.73)$ ，および $178.5 \pm 1.1 \mathrm{HU}(P=0.629)$ であった (Table 2).

ベースおよび模擬腎実質における helical scan と non-helical scan 群間の $P$ 值は，それぞれ 0.689 ，およ び 0.544 であった。

実質相模擬腎囊胞領域の平均 CT 值は, helicalFBP, non-helical-FBP, $70 \mathrm{keV-VMSI，および} \mathrm{MBIR}$ で，それぞれ $11.6 \pm 2.4(P<0.01) ， 11.6 \pm 2.4(P<0.01), 8.6$ $\pm 2.7 \mathrm{HU}(P<0.01) ， お よ ひ ゙ 11.4 \pm 1.4(P<0.001)$ であった (Fig. 5)。また，FBP， 20 mm ビーム幅の helical scan 
Table 2 Averaged CT attenuation values of the 15-mm cyst in base; of the simulated renal parenchyma; of the $15-\mathrm{mm}$ cyst in simulated renal parenchyma phase with 20 -mm aperture for helical-FBP, non-helicalFBP, $70 \mathrm{keV}$-VMSI, and MBIR. The inhibition ratio of pseudoenhancement effect between $40-\mathrm{mm}$ and $20-\mathrm{mm}$ aperture for helical-FBP, $70 \mathrm{keV}$-VMSI, and MBIR.

\begin{tabular}{lcccc}
\hline \hline \multirow{2}{*}{ Protocol } & Scan type & $\begin{array}{c}\text { CT attenuation value [HU] } \\
\text { Cyst areas in the } \\
\text { non-contrast images }\end{array}$ & $\begin{array}{c}\text { Parenchymal areas } \\
\text { around the cyst }\end{array}$ & $\begin{array}{c}\text { Cyst areas in the } \\
\text { contrast images }\end{array}$ \\
\hline \multirow{2}{*}{$120 \mathrm{kV}$-FBP } & Helical & $0.7 \pm 3.0$ & $179.8 \pm 1.7$ & $11.6 \pm 2.4(28.0 \%)$ \\
& Non-helical & $0.2 \pm 1.5$ & $179.3 \pm 1.7$ & $11.6 \pm 2.4$ \\
\hline $70 \mathrm{keV}$-VMSI & Helical & $0.1 \pm 1.4$ & $178.2 \pm 1.6$ & $8.6 \pm 2.7(32.8 \%)$ \\
\hline MBIR & Helical & $0.7 \pm 1.5$ & $178.5 \pm 1.1$ & $11.4 \pm 1.4(29.6 \%)$ \\
\hline & & & \multicolumn{2}{c}{ Values in bracket: inhibition ratio }
\end{tabular}
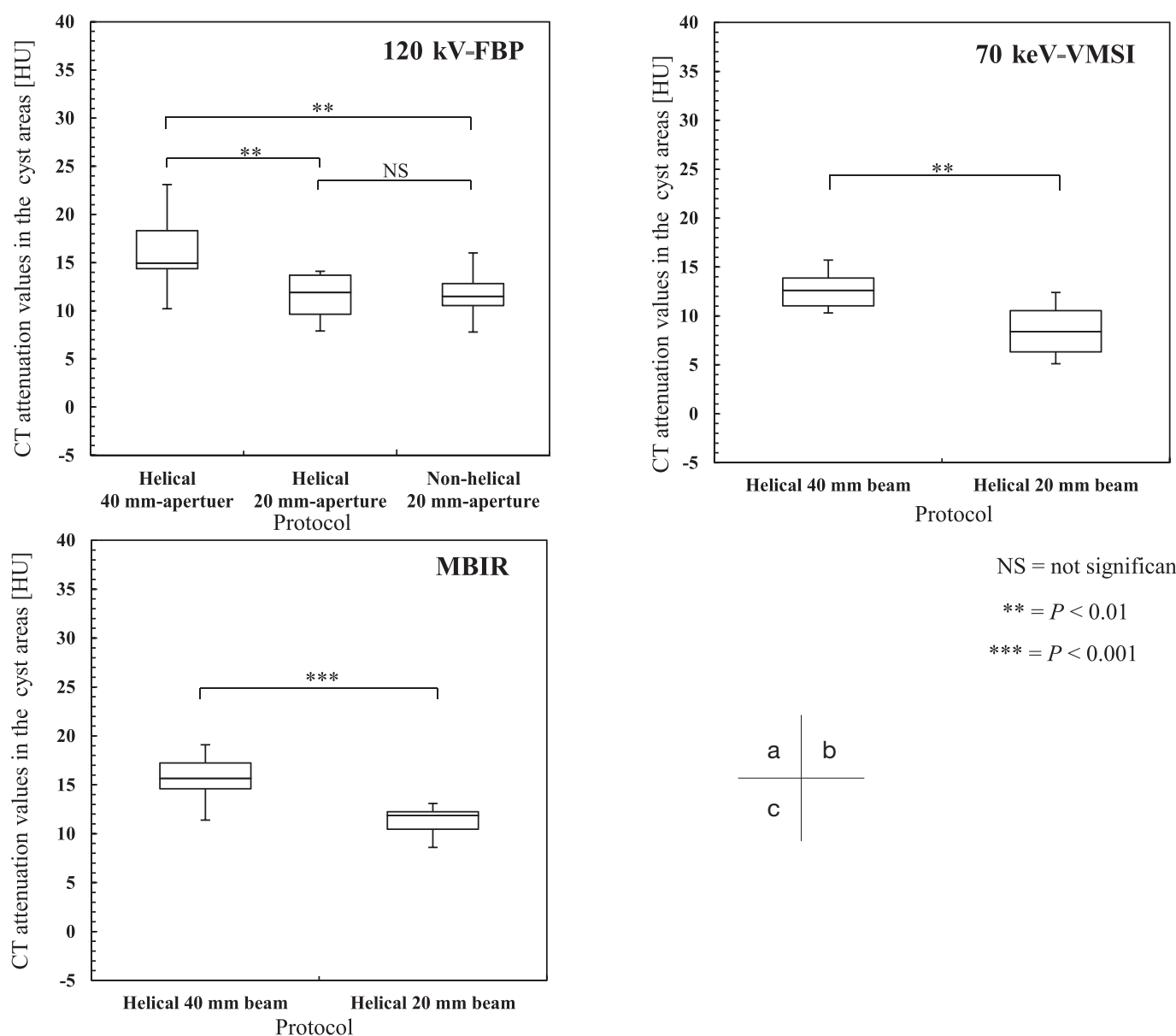

$\mathrm{NS}=$ not significant

** $=P<0.01$

$* * *=P<0.001$

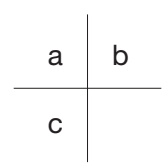

Fig. 5 Comparison of the CT attenuation values for $15-\mathrm{mm}$ cyst in the simulated renal parenchyma-phase with $120 \mathrm{kV}-\mathrm{FBP}, 70 \mathrm{keV}-\mathrm{VMSI}$ and MBIR at different aperture size and scan type.

(a) $120 \mathrm{kV}-F B P$, (b) $70 \mathrm{keV}-\mathrm{VMSI}$; (c) MBIR

$\mathrm{NS}=$ not significant, $* *=P<0.01, * * *=P<0.001$

と non-helical scan 群間の $P$ 值は 1.0 であった。各プ ロトコルに打けるビーム幅 $20 \mathrm{~mm}$ の PE 抑制率を

Table 2 に示す.

\section{3. 考 察}

本研究では partial volume effect の影響を最小限に するため, $1.25 \mathrm{~mm}$ のスライス厚を使用したが, この
影響がゼロになっているわけではない，仮に腎囊胞の モデルを円柱にした場合, 球体と比較して, partial volume effect の存在がなく, 模擬腎囊胞内の CT 值は 少なからず低下傾向を示し, かつスライス厚に依存し ないことが推測できる。これを検証すべく，径 15 $\mathrm{mm}$ の模擬腎囊胞, および $5 \mathrm{~mm}$ のスライス厚におい て, この研究の初期段階で用いた円柱モデルと本研究 

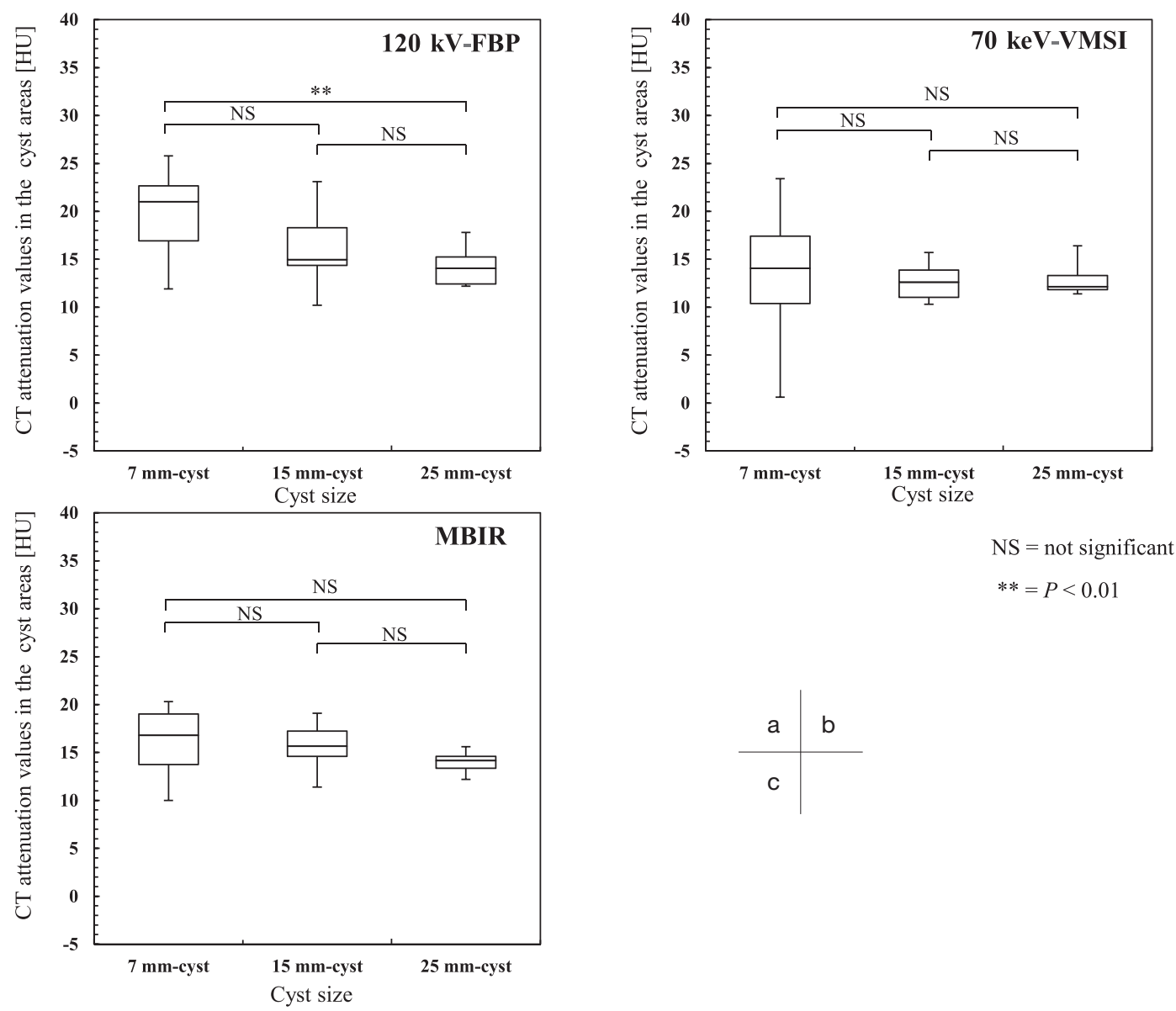

Fig. 6 Comparison of the cyst-CT attenuation values in the simulated renal parenchyma-phase with $120 \mathrm{kV}$ FBP, $70 \mathrm{keV}$-VMSI and MBIR at different cyst sizes.

(a) $120 \mathrm{kV}$-FBP, (b) $70 \mathrm{keV}$-VMSI, (c) MBIR

$\mathrm{NS}=$ not significant, $* *=P<0.01$

で用いた球体モデルによる CT 值の比較を行った。な お模擬実質相の CT 值を $240 \mathrm{HU}$ と高めに，加模擬 腎臓の大きさを $80 \mathrm{~mm}$ と大きめに設定し, PEがより 生じやすい環境下にて実験を行った。その結果，腎囊 胞内の CT 值は円柱モデルと球体モデルで，それぞれ $25.9 \mathrm{HU}$ ，および $29.5 \mathrm{HU}$ となり，円柱モデルで低下 した，更に，スライス厚を薄くするにつれ，そのCT 值は，円柱モデルでは不変であったが, 球体モデルで は低下傾向を示した，後者の傾向は Jinzaki ら ${ }^{9)}$ の臨 床研究による報告と一致し, 球体腎囊胞モデルが人体 に近似していることが示唆された，よって，腎囊胞モ デルを球体にしたことは，妥当であったと考える。

腎囊胞モデルのサイズを $7 \mathrm{~mm}, 15 \mathrm{~mm}$ ，および 25 $\mathrm{mm}$ に設定したことにより, 腎囊胞サイズと PE の関 係も評価できた。従来法 $(120 \mathrm{kV}-\mathrm{FBP}$ ，ビーム幅 40 $\mathrm{mm})$ に対し, $\mathrm{PE}$ による腎囊胞の CT 值増強は, 7 $\mathrm{mm}, 15 \mathrm{~mm}$ ，および $25 \mathrm{~mm}$ 径で，それぞれ 21.9 , 15.8，および $12.7 \mathrm{HU}$ であり，腎囊胞サイズが大きく なるにつれ，CT 值の低下がみられた。また， $7 \mathrm{~mm}$
と $25 \mathrm{~mm}$ 径の群間では有意に低下している。これは PEのサイズ依存を表しており，実臨床において，大 きな腎腫瘤性病変ほど PE が低下し，鑑別しやすくな ることを示唆している，本研究では囊胞サイズと $\mathrm{PE}$ の関係を明らかにできたと考える (Fig. 6).

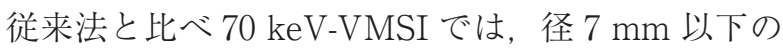
サイズに対する腎囊胞内の CT 值は有意に低下し，そ の $\mathrm{PE}$ 抑制率は $36 \%$ であった。しかしながら, 先行研 究である Jung ${ }^{21)}$ の検討では, その抑制率は 49\%で あり, 本実験と相違している。この要因として, 彼ら が使用した模擬腎実質の CT 值が $240 \mathrm{HU}$ と, 実臨床 と比べ高值であったことが考えられる。また，この報 告 ${ }^{21)}$ では, 腎囊胞内の CT 值は $120 \mathrm{kV}-\mathrm{FBP}$ で $42 \mathrm{HU}$ と高值であることから， BH が増大する環境下では 70 keV-VMSI の PE 抑制率も増大傾向があることを示し ている.

本実験から $70 \mathrm{keV}-\mathrm{VMSI}$ はPE 抑制に有用である ことが示唆された。また, $120 \mathrm{kV}-\mathrm{FBP}$ と $70 \mathrm{keV}$ VMSI に対する腎実質の CT 值に有意差が認められな 
かったことから, $120 \mathrm{kV}$ と同等なVMSIのエネル ギーとして, $70 \mathrm{keV}$ の選択は妥当であり, 先行論 文 $^{14,15,22)}$ とも一致した.

MBIR は光学的モデルを計算に取り入れた画像再構 成法 ${ }^{18,19)}$ であり，PE 抑制効果を期待したが，FBP と 比べ有意差は生じなかった。これはYamada ら ${ }^{22)} の$ 臨床研究と一致し, 妥当な結果といえる.

従来法である $40 \mathrm{~mm}$ ビーム幅と比較して $20 \mathrm{~mm}$ ビーム幅の PE 抑制率は FBP, $70 \mathrm{keV}$-VMSI，および MBIR で腎囊胞内の CT 值は有意に低下し，そのPE

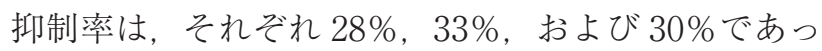
た.この結果は検出器の列数と腎囊胞の PE の関係を 検証した先行研究3.7.10) と一致した。ビーム幅が広く なるほど, PEが生じており, 散乱線の影響が強く考 えられる。これを確かめるため, 散乱線が限りなく少 ない状況を想定すべく，ビーム幅を $1.25 \mathrm{~mm}$ (nonhelical modeのみの仕様)にして本実験を行った，そ の結果, 腎囊胞の CT 值は $5.5 \mathrm{HU}$ となり, 従来法と比 べた PE 抑制率は 53\%であった。この結果を踏まえ ると散乱線が確実にPEに影響を及ぼしているといえ る.しかしながら, non-helical scan, $1.25 \mathrm{~mm}$ のビー ム幅を用いることは, 臨床上，スキャン時間の増加に つながり有用とはいえない，PEへの散乱線の影響を 考えると, 近年, XY 方向に加え体軸方向の散乱線も 除去できる 3-dimensional grid を搭載したCT 装置が 登場しており，その有用性が大いに期待できる。

同じビーム幅 $(20 \mathrm{~mm})$ に扔ける helical scan と nonhelical scan での腎囊胞の CT 值は同等であったこと から，スキャンタイプは PE に影響を及ぼさないと考 える。

本研究では, 実臨床に基づき従来法の管電圧を 120

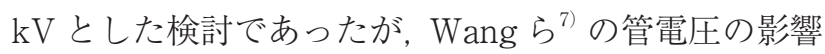
に関して検討した先行研究によると, 低電圧ほど $\mathrm{PE}$ が抑制されると報告しているが，疑問が残る，本ファ ントムを用いた PE と管電圧の関係を立証する必要性
を強く感じた. Pitch factor も管電圧同様, 実臨床に 基づき 1.375 のみでの検討であったが, 研究の前段階 で pitch factor は PE 抑制に影響がないことが確認で きていたため検討項目から省略した。

本研究の限界は, 他のデー夕収集方式で得られる VMSI，および逐次近似画像再構成法では検討に至っ て抢らず，同じ結果になるかどうか明らかにしていな い点である。

本研究から, 従来法 $(120 \mathrm{kV})$ と同等のエネルギーを 考慮した場合，腎囊胞の PE 抑制に有用であった撮影 条件は, $70 \mathrm{keV}-\mathrm{VMSI}$ および $20 \mathrm{~mm}$ ビーム幅の選択 であった。

\section{4. 結 語}

人体に近似したファントムを用い, 腎囊胞の PE 抑 制に関わる $\mathrm{CT}$ 撮影条件を，撮影エネルギーの違い

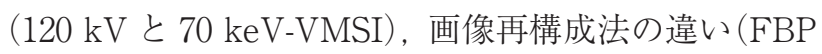
と MBIR)，抢よびビーム幅の違い (40 mm と $20 \mathrm{~mm})$ について検討した，その結果， $15 \mathrm{~mm}$ 以下の腎囊胞 では, $120 \mathrm{kV}$ のエネルギーとの比較において, 同等の エネルギーである $70 \mathrm{keV}-\mathrm{VMSI}$ の有用性が検証でき た。一方，MBIRの有用性は認められなかった。ま た，狭いビーム幅を選択することで PEが抑制される ことを明らかにできた。 $120 \mathrm{kV}-\mathrm{FBP} に$ に比して，PE 抑 制効果に有用な撮影条件は, 狭いビーム幅と $70 \mathrm{keV}$ VMSI の使用であることが, 本研究で導き出すことが できた。

\section{謝 辞}

本研究を進めるにあたり，ご協力いただきました当 院放射線技術室室長の渡部敏男様, ならびにCT 担当 スタッフの諸賢に深謝いたします。

なお, 本論文の基礎的内容は第 1 回日本 CT 技術学 会(2013 年, 広島)にて発表した。

\section{参考文献}

1) Bosniak MA. The current radiological approach to renal cysts. Radiology 1986; 185(1): 1-10.

2) Chung EP, Herts BR, Linnell G, et al. Analysis of changes in attenuation of proven renal cysts on different scanning phases of triphasic MDCT. AJR Am J Roentgenol 2004; 182(2): 405410.

3) Sai V, Rakow-Penner R, Yeh BM, et al. Renal cyst pseudoenhancement at 16- and 64-dector row MDCT. Clin Imaging 2013; 37(3): 520-525.

4) Tappouni R, Kissane J, Sarwani N, et al. Pseudoenhancement of renal cysts: influence of lesion size, lesion location, slice thickness, and number of MDCT detectors. AJR Am J Roentgenol 2012; 198(1): 133-137.

5) Bae KT, Heiken JP, Siegel CL, et al. Renal cysts: is attenuation artifactually increased on contrast-enhanced CT images? Radiology 2000; 216(3): 792-796.

6) Maki DD, Birnbaum BA, Chakraborty DP, et al. Renal cyst pseudoenhancement: beam-hardening effects on CT numbers. Radiology 1999; 213(2): 468-472.

7) Wang ZJ, Coakley FV, Fu Y, et al. Renal cyst pseudoenhance- 
ment at multidetector CT: what are the effects of number of detectors and peak tube voltage? Radiology 2008; 248(3): 910916.

8) Coulam CH, Sheafor DH, Leder RA, et al. Evaluation of pseudoenhancement of renal cysts during contrast-enhanced CT. AJR Am J Roentgenol 2000; 174(2): 493-498.

9) Jinzaki M, McTavish JD, Zou KH, et al. Evaluation of small $(</$ $=3 \mathrm{~cm}$ ) renal masses with MDCT: benefits of thin overlapping reconstructions. AJR Am J Roentgenol 2004; 183(1): 223-228.

10) Birnbaum BA, Hindman $N$, Lee $J$, et al. Renal cyst pseudoenhancement: influence of multidetector CT reconstruction algorithm and scanner type in phantom model. Radiology 2007; 244(3): 767-775.

11) Lehmann LA, Alvarez RE, Macovski A, et al. Generalized image combinations in dual KVP digital radiography. Med Phys 1981; 8(5): 659-667.

12) Kalender WA, Perman WH, Vetter JR, et al. Evaluation of a prototype dual-energy computed tomographic apparatus. I. Phantom studies. Med Phys 1986; 13(3): 334-339.

13) Vetter JR, Perman WH, Kalender WA, et al. Evaluation of a prototype dual-energy computed tomographic apparatus. II. Determination of vertebral bone mineral content. Med Phys 1986; 13(3): 340-343.

14) Matsumoto K, Jinzaki M, Tanami $Y$, et al. Virtual monochromatic spectral imaging with fast kilovoltage switching: improved image quality as compared with that obtained with conventional 120-kVp CT. Radiology 2011; 259(1): 257-262.

15) Yamada M, Jinzaki M, Kuribayashi S, et al. Beam-hardening correction for virtual monochromatic imaging of myocardial perfusion via fast-switching dual-kVp 64-slice computed tomography: a pilot study using a human heart specimen. Circ J 2012; 25; 76(7): 1799-1801.
16) Yamada Y, Jinzaki M, Tanami Y, et al. Virtual monochromatic spectral imaging for the evaluation of hypovascular hepatic metastases: the optimal monochromatic level with fast kilovoltage switching dual-energy computed tomography. Invest Radiol 2012; 47(5): 292-298.

17) Yamada Y, Jinzaki M, Hosokawa T, et al. Abdominal CT: an intra-individual comparison between virtual monochromatic spectral and polychromatic 120-kVp images obtained during the same examination. Eur J Radiol 2014; 83(10): 1715-1722.

18) Thibault JB, Sauer KD, Bouman CA, et al. A threedimensional statistical approach to improved image quality for multislice helical CT. Med Phys 2007; 34(11): 4526-4544.

19) Yu Z, Thibault JB, Bouman CA, et al. Fast model-based X-ray $\mathrm{CT}$ reconstruction using spatially nonhomogeneous ICD optimization. IEEE Trans Image Process 2011; 20(1): 161-175.

20) Yamada Y, Jinzaki M, Tanami Y, et al. Model-based iterative reconstruction technique for ultralow-dose computed tomography of the lung: a pilot study. Invest Radiol 2012; 47(8): 482489.

21) Jung DC, Oh YT, Kim MD, et al. Usefulness of the virtual monochromatic image in dual-energy spectral CT for decreasing renal cyst pseudoenhancement: a phantom study. AJR Am J Roentgenol 2012; 199(6): 1316-1319.

22) Yamada Y, Yamada M, Sugisawa K, et al. Renal cyst pseudoenhancement: Intraindividual comparison between virtual monochromatic spectral images and conventional polychromatic $120-\mathrm{kVp}$ images obtained during the same CT examination and comparisons among images reconstructed using filtered back projection, adaptive statistical iterative reconstruction, and model-based iterative reconstruction. Medicine 2015; 94(15): 1-8. 